\title{
CORRESPONDENCE
}

\section{Penh is not a measure of airway resistance!}

\section{To the Editors:}

We wish to express serious concern about an article in the current issue of the European Respiratory Journal, in which MEHTA et al. [1] reported the effects of choline treatment on airway hyperresponsiveness using unrestrained plethysmography to derive enhanced pause (Penh) as a measure of lung function. In the Methods section of their paper, MEHTA et al. [1] refer to a previous study by LUNDBLAD et al. [2] in support of their statement: "Lung function was recorded and calculated as enhanced pause (Penh), which correlates with pulmonary resistance [2]." In fact, LUNDBLAD et al. [2] argued precisely the opposite, emphasising that unrestrained plethysmography accurately reflects airway resistance only if the gas in the plethysmograph is pre-conditioned to body temperature and humidity, and if functional residual capacity and tidal volume are measured independently. Indeed, it has been shown that Penh may not correlate at all with lung mechanical function [3, $4]$, and a distinguished group of experts has pointed out that it is scientifically unacceptable to report Penh as a measure of respiratory mechanical function [5].

The mechanical properties of the lungs are characterised by its main determinants, resistance and elastance. The resistance is the ratio of the pressure to the flow, while the elastance is the ratio of the pressure to the volume. Therefore, to calculate either of these quantities two signals need to be measured, namely pressure and either flow or volume. Penh is based on only a single time-varying signal, the pressure inside a plethysmograph, so it simply does not contain the information required to provide a valid estimate of lung mechanics. At best, Penh represents some kind of nonspecific reflection of the pattern of breathing [3]. MEHTA et al. [1] report that intranasal administration of choline was more effective than oral administration in reducing Penh. What this means in terms of the effects of choline on lung mechanics is anyone's guess, and could mean nothing at all. Moreover, because mice are obligatory nose breathers, Penh includes the mechanical properties of the nose which may be altered by intranasal delivery. Penh has been thoroughly discredited as a measure of respiratory mechanics, and reviewers, editors and journals should not accept any study that uses this quantity and claims it represents airway or pulmonary resistance.

\section{L.K.A. Lundblad*, C.G. Irvin*, Z. Hantos", P. Sly", W. Mitzner ${ }^{+}$and J.H.T. Bates*}

*Vermont Lung Center, University of Vermont, Burlington, VT and ${ }^{+}$Division of Physiology, Johns Hopkins Bloomberg School of Public Health, Baltimore, MD, USA. "Dept of Medical Informatics and Engineering, University of Szeged, Szeged, Hungary. "Telethon Institute for Child Health Research, University of Western Australia, Perth, Australia.

\section{STATEMENT OF INTEREST}

None declared.

\section{REFERENCES}

1 Mehta AK, Gaur SN, Arora N, Singh BP. Effect of choline chloride in allergen-induced mouse model of airway inflammation. Eur Respir J 2007; 30: 662-671.

2 Lundblad LKA, Irvin CG, Adler A, Bates JHT. A reevaluation of the validity of unrestrained plethysmography in mice J Appl Physiol 2002; 93: 1198-1207.

3 Adler A, Cieslewicz G, Irvin CG. Unrestrained plethysmography is an unreliable measure of airway responsiveness in BALB/c and C57BL/6 mice J Appl Physiol 2004; 97: 286-292.

4 Petak F, Habre W, Donati YR, Hantos Z, BarazzoneArgiroffo C. Hyperoxia-induced changes in mouse lung mechanics: forced oscillations versus barometric plethysmography J Appl Physiol 2001; 90: 2221-2230.

5 Bates JHT, Irvin CG, Brusasco V, et al. The use and misuse of Penh in animal models of lung disease Am J Respir Cell Mol Biol 2004; 31: 373-374.

DOI: $10.1183 / 09031936.00091307$

\section{Particulate matter, science and European Union policy}

\section{To the Editors:}

The editorial of ANNESI-MAESANO et al. [1] summarises current evidence concerning the adverse health effects of particulate matter (PM) and correctly outlines that: 1) the health effects of air pollution are a big problem worldwide; and 2) several scientific questions are still open. In addition, the authors press for more stringent measures of prevention, in order to achieve adequate protection of the exposed population. In particular, they outline that "experimental research has rapidly progressed" and only "details of the pathophysiological mechanisms remain to be elucidated".

We agree with most of their statements and are in favour of more stringent rules for the European Union (EU). However, we would like to make some comments concerning the open questions, in order to increase the scientific strength that should convince EU authorities. 